\title{
Criterios de intervención en el centro histórico de Ferrara: de las políticas de reconstrucción tras la Guerra Mundial al Plan de Rehabilitación Integral ${ }^{*}$
}

\author{
Miguel ÁNGel Chaves Martín \\ Profesor Titular de Arte Contemporáneo. Dpto. de Comunicación Audiovisual y Publicidad II. \\ Facultad de Ciencias de la Información. Universidad Complutense de Madrid \\ machaves@ucm.es
}

Pese a la sorprendente escasez y relativa falta de interés que hasta fechas recientes se ha evidenciado en la bibliografía en castellano, la importancia histórica de la ciudad de Ferrara y su desarrollo urbano no dejan lugar a dudas. Jacob Burckhardt la definió ya en el siglo XIX como la primera ciudad moderna de Europa (Burckhardt, 1983), definición que sería retomada cien años después por Bruno Zevi cuando, entre 1960 y 1971 lleve a cabo sendos estudios sobre la ciudad y su arquitecto Biagio Rossetti como modelo ejemplar de planificación urbana en el Renacimiento ${ }^{1}$. Desde entonces, la ciudad

\footnotetext{
* Una primera versión de este artículo se publicó en la revista digital de arte contemporáneo Arte2o. (Junio, 2003) Criterios de intervención en los centros históricos italianos: el modelo de Ferrara. ${ }^{1}$ El primer estudio de Zevi fue Biagio Rosseti architetto ferrarese, il primo urbanista moderno europeo (Torino, 1960), ampliado posteriormente con su obra Saper vedere l'urbanistica. Ferrara di Biagio Rossetti, la prima città moderna europea (Torino, 1971). Desde entonces se sucedieron los estudios por parte de Francesca Bocchi (1974), Adriano Franceschini (1969), Carlo Bassi (1980), Giusepe Papagno (1982), Werner Gundersheimer (1988) Ada Francesca Marcianò (1992) y Thomas Tuohy (1996) entre otros. En castellano, una revisión bibliográfica del proceso urbanístico de Ferrara en Miguel Angel Chaves (2001 y 2012).
} 
conoció un interesante proceso de transformación urbana que alcanza de nuevo valor de referencia en la década de 1970 con el desarrollo del plan de ordenación del centro histórico y su integración con el territorio.

Mediado el siglo XX vamos a encontrarnos con una Ferrara heredera de la forma renacentista del proyecto rossettiano sobre la que se han ido sucediendo puntuales intervenciones, primero a través de la desecación de los canales convertidos en nuevas avenidas, y después con la aparición de un nuevo hito urbano ubicado al suroeste de la ciudad en torno a la Fortaleza de los Papas. Especulación, cambio de funciones sociales en el centro, aparición de eclecticismos e historicismos, puntuales muestras de Art Nouveau en villas suburbanas y ejemplos diseminados de construcciones fascistas oscilando entre el racionalismo y la romanidad clasicista, fueron configurando un espacio urbano de indudable interés a lo largo de estos siglos.

Sobre esta realidad y tras los bombardeos de la Segunda Guerra Mundial, se iniciará la necesaria reconstrucción. Son momentos de incertidumbre, de especulación, de prisas por construir y, como consecuencia, de intervenciones poco afortunadas dentro del centro histórico. A finales de la década de 1950 la situación comenzará a cambiar. Un congreso celebrado en la ciudad en 1958 pondrá públicamente de manifiesto la problemática en la que se desenvuelven los centros históricos en ese momento. El interés por la cultura urbanística y la conservación de la ciudad crece a medida que nos adentramos en la década de los '60 para culminar en los años '70 de la pasada centuria con las consecuencias del denominado "hito" de Bolonia y la Declaración de Amsterdam sobre el Patrimonio Europeo de 1975. Ferrara empieza entonces a elaborar un plan que se convirtió, quinientos años después de la denominada Adición Hercúlea de Biagio Rossetti, en un nuevo modelo de planificación, gestión, conservación y rehabilitación integral del centro histórico y su territorio.

Hasta la última posguerra la ciudad ha coincidido básicamente con el centro histórico. Esto implicó un uso sistemático y una compleja estructura de carácter capitalista en el centro histórico (desarrollo del sector terciario, especulación inmobiliaria, marginación, problemas de suelo urbano, etc.) en un proceso aún hoy irreversible. Es más, el planeamiento de posguerra (Plan de Reconstrucción de 1949 y Piano Regolatore Generale de 1957) han racionalizado sustancialmente tal estructura, por la cual hoy el centro histórico es expresión del "poder 
político", con sus sedes administrativa y sociopolítica, del "poder económico", con el comercio, los grandes almacenes y el consumo privado, y de la denominada "cultura de la ciudad", centrada en la Universidad, los museos, bibliotecas, pinacoteca, obras sociales y tiempo libre. En conclusión, se puede decir que hoy el centro histórico se ha reservado prioritariamente a funciones terciarias que han cambiado por completo su papel y valores de uso ${ }^{2}$.

Las palabras de Carlo Cesari, referidas a la situación de la ciudad a finales de los años '60, definen perfectamente el estado en que se encontraba el centro histórico de Ferrara a caballo entre la reconstrucción tras la guerra y los nuevos criterios de conservación y rehabilitación que empezaban a imponerse a partir de la Carta de Venecia de 1964.

La nueva situación intentaba poner remedio a anteriores fracasos, como el de la Ley Urbanística Nacional de 1942 o las leyes de Tutela y Protección del Patrimonio Artístico y Monumental de 1939. Evidentemente, en pleno conflicto bélico y a un año de la derrota fascista, la población estaba preocupada por temas mucho más graves como para perder el tiempo en leyes urbanísticas. Por otro lado, la operatividad de esta nueva legislación se limitaba a aquellos edificios inscritos en la Lista del Patrimonio Monumental Declarado, o también si la calidad del tejido a transformar contenía valores artísticoambientales. $Y$ todo ello con innumerables excepciones, errores y abusos que no podemos ni siquiera enumerar ahora. El resto, que era la mayoría, amparado por la Ley de 1942, podía ser completamente alterado. De hecho, la citada ley no incluía ninguna disposición especial sobre la planificación de la que podemos denominar "Ciudad Antigua" o centro histórico. La situación, por tanto, no era excesivamente buena. Dentro de las tres generaciones urbanísticas señaladas por Campos Venuti a lo largo de la segunda mitad del siglo XX, la primera de ellas será la de Reconstrucción tras el final de la Segunda Guerra Mundial. Las destrucciones fueron masivas en toda Europa y la reconstrucción era completamente necesaria, desarrollándose planes y programas de intervención de especial relevancia y repercusión en ciudades como Londres o Varsovia. Caso aparte fue Italia, donde los planes urbanísticos brillaron

\footnotetext{
${ }^{2}$ Carlo Cesari. "Il Piano Regolatore ed il programma di recupero e valorizzazione del patrimo-
} nio architettonico di Ferrara". Il passato per un nostro avvenire. Ferrara, 1980, pág. 56. 
por su ausencia, levantándose de nuevo los inmuebles bombardeados con un volumen dos veces mayor que el destruido. Para afianzar aún más esta situación el gobierno llegó a dejar en suspenso la aplicación de la Ley de 1942,

que obligaba a disponer de un plan urbanístico en todo el territorio municipal, imponiendo a los Planes de Reconstrucción que se ocuparan exclusivamente de las zonas destruidas, deliberadamente aisladas del contexto urbano y territorial. La intención explícita no era austera, ni modesta, sino más bien la de atraer el capital especulativo privado hacia la reconstrucción, negándose a asignar las áreas bombardeadas a nuevos jardines o a servicios públicos, y asignándolas más bien a oficinas y viviendas de lujo, con indices de edificabilidad muy superiores a los de las construcciones destruidas (Campos Venuti, 1994: 20).

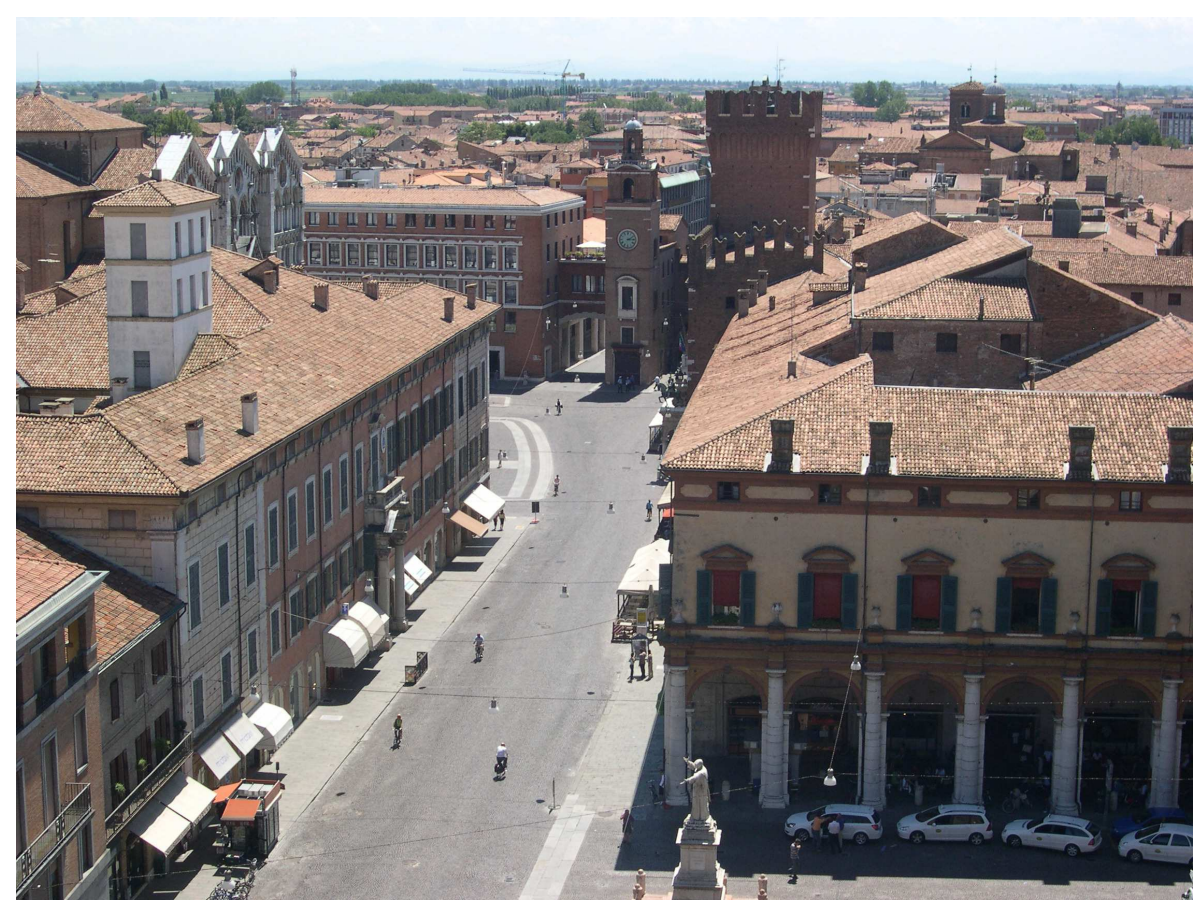

Por lo que respecta a la conservación de la ciudad, durante estos años "reconstruir" no tenía el mismo significado que "recuperar" un patrimonio inmobiliario y un sistema económico, sino crear un reclamo de capitales: era la operación la que era rentable, no el producto. El resultado fue que en Italia en 
la década de 1950 se destruyó más con la Reconstrucción que lo que habían destruido los bombardeos (Cesari, 1989: 57)3. Una de las políticas más destacadas será la de construcción de viviendas sociales, en las que el INA (Istituto Nazionale delle Assicurazioni) jugó un papel fundamental. Precisamente la creación de barrios obreros provocará el desplazamiento de la reconstrucción del centro histórico hacia la periferia. Pero allí no va a haber Planes de Ordenación sino simples Programas de Construcción de Vivienda con "Indices Volumétricos de Áreas", tanto si están demolidas como si no.

Esta década de 1950 será para Italia la del denominado "milagro económico" y su consiguiente expansión urbana, a partir sobre todo de 1955, y alcanzado su apogeo en la década siguiente. La reconstrucción ha quedado atrás y ahora las ciudades empezarán a extenderse como manchas de aceite por el territorio a medida que aumenta su riqueza, su industria, la mano de obra y, en consecuencia, la necesidad de viviendas. La contrapartida será una evidente falta de planificación y un pobre diseño en medio de un desequilibrio cada vez más preocupante entre campo y ciudad.

En el sector de la construcción, tras las intervenciones del período 19451949, dirigidas a la recuperación del patrimonio inmobiliario dañado en la guerra, los años '50 suponen una intervención masiva del Estado, tanto para hacer frente a la urgencia de reconstruir el patrimonio destruido, como para satisfacer la creciente demanda de nuevas viviendas. Son años de despoblamiento rural, de éxodos masivos a la ciudad, a los grandes centros administrativos e industriales; pero también serán los años de la evidente desarmonía entre la ciudad y su economía, entre la población y los recursos con los que cuentan. Es entonces cuando veremos aparecer las primeras reacciones ante el tratamiento desmembrado e incorrecto del Patrimonio Histórico y Monumental, con denuncias y escándalos que empiezan a salir a la luz gracias a la labor

\footnotetext{
${ }^{3}$ En este sentido el propio Cesari (op. cit., 57) aporta un elocuente texto del historiador Mario Ridolfi del año 1952 en el que afirma que las ciudades históricas italianas que en el pasado habían tenido la fortuna de ver acrecentar su patrimonio, fruto del nivel cultural de las gentes de entonces, asisten ahora a la transferencia de la promoción a unos anónimos operadores económicos, motivados por la mera razón mercantil. Por lo tanto, prevalece el triunfo de la ignorancia que ve a administradores, propietarios, operadores y falsos proyectistas celebrar banquetes sobre las ruinas de las ciudades dañadas por la mano del hombre a causa de los acontecimientos bélicos, pero todavía más por la reconstrucción.
} 
de asociaciones como "Italia Nostra" y ANCSA (Asociación Nacional de Centros Históricos y Artísticos).

En medio de este panorama se celebra en Ferrara el año 1958 un primer Congreso Nacional en torno al problema de la conservación de los centros históricos, las causas de su degradación y las posibles formas de actuación. La primera conclusión fue que las acciones de destrucción sucedían inevitablemente como consecuencia de una legislación italiana que ignoraba la conservación, legalizaba el libre arbitrio de la propiedad, e incluso legitimaba las transformaciones y las sustituciones. El derecho de propiedad, las diferentes normas de higiene y los reglamentos de construcción daban la facultad de intervenir con transformaciones que acabaron por comprimir la ciudad misma, determinando condiciones de vida insostenibles y por lo tanto llegando a una auténtica destrucción de los presupuestos económicos, motivo inicial de las transformaciones (Cesari, 1989: 58). El error, en palabras del congresista Corrado Beguinot, derivaba

de la torpeza de querer tratar, en la gestión de la ciudad, en términos arquitectónicos, problemas que son eminentemente urbanísticos. La tutela y la recuperación de los centros históricos, por lo tanto, han de ser planificadas, y no propuestos a trámite proyectos de restauración de los diversos edificios. El problema es que esta planificación no puede ser ya la del "zonning" de la Ley Urbanística, válida para las áreas nuevas, sino una metodología de intervención, pactada con todas las componentes políticas y sociales interesadas, y sobre la base de programas operativos.

Si bien las recomendaciones de Ferrara no pasaron de un programa de intenciones sin operatividad, pronto empezaron a realizarse investigaciones mucho más cuidadas y complejas sobre los centros históricos, plasmadas en casos como los de Gubbio, Siena y Venecia en la década de 1960. Son los años, en Ferrara, de la ejecución del Piano Regolatore Generale de 1957 y el posterior desarrollo de la construcción con la creación de nuevos barrios, viviendas sociales y zonas periféricas que extienden la ciudad más allá de los límites del centro histórico. Los años finales de los sesenta y los primeros setenta suponen para Ferrara un importante crecimiento urbano, generalmente controlado por el Ayuntamiento y con resultados positivos en la creación de barrios 
obreros extramuros, que dejan de convertirse en ghettos periféricos para ser centros residenciales plenamente insertados en el tejido urbano, dotados de todos los servicios necesarios: espacios ajardinados, zonas verdes, escuelas, aparcamientos, etc.

Durante esa década de los sesenta va a continuar el proceso de terciarización de los centros históricos, aunque ahora, al menos, las demoliciones y reconstrucciones quedarán relegadas ante un nuevo criterio de recuperación, más o menos correcto, de la arquitectura histórica, si bien, con relativa frecuencia, asistiremos a completos vaciados de edificaciones de las que solo se ha respetado alguna de sus fachadas.

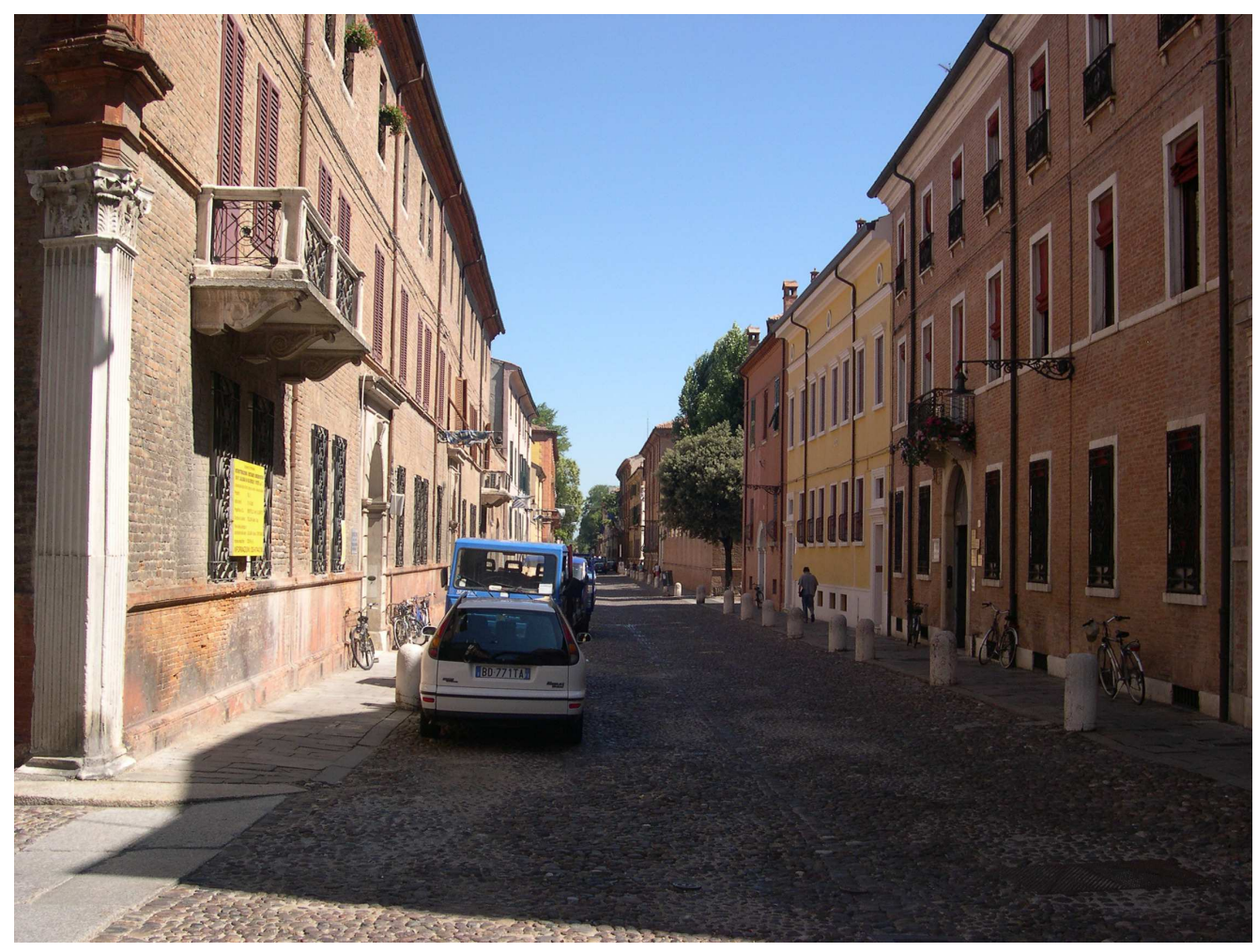

Crece considerablemente el interés por la cultura urbanística, generalizándose ahora la idea de que hay que intervenir de manera orgánica y armónica en el sector de la construcción, valorando y teniendo presente todas las necesidades, mejorando el nivel de vida, preocupándose no sólo de la creación de 
casas sino también de su inserción, de su ajuste dentro de un tejido urbano racionalmente concebido. Como contrapartida, esto va a provocar una ralentización en las intervenciones a las que se suma la crisis económica de 19631965, agravándose aún más en la década de 1970.

La aparición de la Carta de Venecia en 1964 y la creación de ICOMOS (Consejo Internacional de Monumentos y Sitios) constituyen un hito esencial en este proceso. Con sus virtudes y sus carencias, el documento de Venecia fue una buena síntesis de la situación que presentaba el problema urbano y patrimonial en ese momento, defendiendo el principio de autenticidad sobre los cada vez más frecuentes "falsos históricos", y la valoración del monumento en su conjunto, no como obra aislada sino como parte de los revitalizados ámbitos urbanos y rurales.

Los centros históricos se habían convertido en un problema cada vez más preocupante. Las políticas de intervención seguían sin resolver su galopante deterioro, no sólo monumental sino también urbanístico, económico y social, con alteración de funciones y pérdida de sus valores tradicionales. La respuesta, avanzada por la Carta de Venecia, se vio fortalecida a finales de la década con el plan de Bolonia elaborado por Pier Luigi Cervellati, verdadero "hito" y modelo en los criterios de intervención en centros históricos. La denominada "nueva cultura de las ciudades" empezaría entonces a redefinir y clarificar términos como "centro histórico", "monumento", "arquitectura", "edificación", etc., y a fomentar las políticas de intervención y recuperación de las viejas ciudades italianas (riuso urbano) durante la segunda mitad de la década de 1970, con cinco objetivos fundamentales (Pol, 1980):

- Recuperar el tejido residencial deteriorado.

- Refuncionalizar el capital fijo social existente.

- Reutilizar socialmente los contenedores arquitectónicos infrautilizados o privatizados.

- Recualificar el ambiente urbano.

- Proteger y valorar el medio natural.

De esta manera pasamos a la denominada por Campos Venuti "tercera generación urbanística", esto es, la de la transformación una vez realizada la expansión en años precedentes, que culminará en la década de los ochenta En su desarrollo no sólo será importante el "hito de Bolonia" sino también la 
aparición de la Carta Europea del Patrimonio Arquitectónico de 19754 Las consecuencias serán una nueva situación socio-política, nuevas posibilidades económicas, obsolescencia y carencia de respuestas por parte de los conservacionistas, comienzo de una crítica social de un desarrollo de la ciudad producido desde respuestas meramente tecnológicas y de sus repercusiones socioeconómicas; un conjunto de factores, en definitiva, que, unidos al desarrollo de nuevas metodologías para el análisis de centros históricos, producidas por una nueva generación de "conservadores", de arquitectos "externos" cultos, consiguieron que una formulación, en parte integradora y en parte rupturista, tuviera éxito (García Gil, 1989: 32).

Será el Plan para la ciudad de Livorno de 1975 el que, urbanísticamente hablando, se constituya en el primer plan italiano globalmente apoyado, tanto desde el punto de vista metodológico como político, en la estrategia del ya citado riuso urbano.

Por lo que a la rehabilitación se refiere, el momento determinante en la consolidación y generalización de esta política de riuso llegará con la nueva Ley de la Vivienda de 1978, cerrándose así la etapa "experimental" iniciada a finales de la década de 1960. La nueva ley supuso la inserción orgánica de la política de rehabilitación y recuperación del patrimonio existente en el conjunto de la política de vivienda, en tanto que las determinaciones estructurales de esa disposición engloban, de forma articulada, actuaciones de recuperación (Planes de recuperación del patrimonio residencial y urbano) y de nueva edificación (viviendas sociales), tanto en régimen de promoción pública como en régimen "protegido-concertado" (García Gil, 1989: 34).

Los aludidos Planes de recuperación del patrimonio residencial y urbano ofrecían cinco unidades mínimas de actuación contempladas en la nueva ley. En primer lugar se hablaba de intervenciones de conservación ordinaria, destinadas a la reparación y mantenimiento de acabados e instalaciones. En segundo lugar, intervenciones de conservación extraordinaria, en la que se incluyen obras y modificaciones en edificios con destino a su renovación, siem-

\footnotetext{
${ }^{4}$ Mientras que Campos Venuti (1994) habla de tres generaciones urbanísticas durante la segunda mitad del siglo XX en Italia, Carlo Cesari (1989) apunta hasta cinco generaciones en cuanto a Planes de Intervención en Centros Históricos se refiere: 1960-65; 1965-70; 1970-75; 1975-80; 1980-85, aña-diendo una última generación desde 1985 hasta hoy.
} 
pre y cuando no afecten ni a los volúmenes, ni a las superficies ni supongan un cambio de uso. En tercer lugar, intervenciones de restauración y "risanamento conservativo"5, conformado por obras de consolidación, recuperación y renovación de los elementos constitutivos del edificio, manteniendo sus características de uso y eliminando elementos contradictorios y ajenos al organismo arquitectónico ${ }^{6}$. En cuarto lugar, intervenciones de reestructuración edificatoria, con obras que permiten la sustitución o recuperación de elementos constitutivos del edificio a la vez que la inclusión de elementos e instalaciones nuevos. Finalmente, intervenciones de reestructuración urbanística, que comprenden las operaciones dirigidas a la sustitución del tejido urbanístico y del tejido edificado existente por otro diferente, mediante un conjunto sistemático de actuaciones que pueden suponer la modificación del trazado de las parcelas, de las manzanas y de la red viaria (Pol, 1980: 46-48).
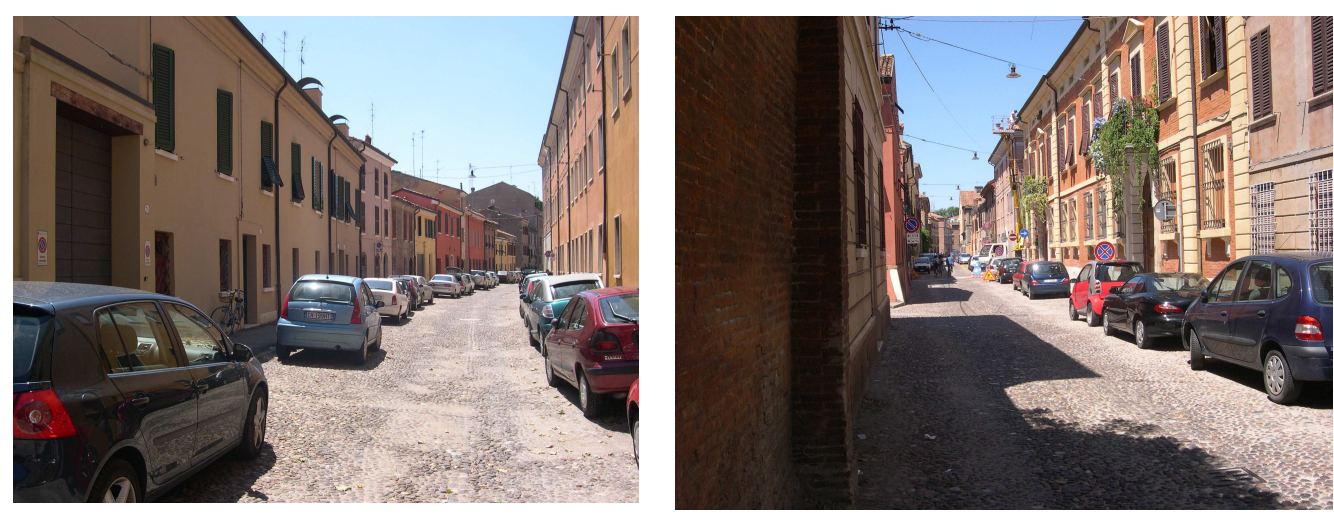

El desarrollo y especificación de estas categorías corresponde a las diferentes regiones italianas con competencias legislativas en esta materia, correspondiendo el caso de Ferrara a la región de Emilia-Romagna. La Ley de protección

\footnotetext{
${ }_{5}^{5}$ Seguimos el planteamiento de Francisco Pol (1980: 46) también en lo que se refiere al término risanamento conservativo, en tanto que su contenido conceptual -resultado de su formación en el marco de los análisis teóricos, los debates culturales y las verificaciones operativas de los años 60- rebasa las connotaciones de los términos castellanos usuales, escasamente formalizados, como consecuencia de la escasa elaboración de esta problemática en nuestra área cultural.

${ }^{6}$ La Ley de Protección y Uso del Territorio para la Emilia-Romagna aprobada en diciembre de 1978 entiende por restauración o risanamento conservativo aquellas intervenciones dirigidas a conservar el organismo arquitectónico y a asegurar su funcionalidad mediante un conjunto sistemático de obras que, respetando los elementos tipológicos, formales y estructurales del organismo, permitan unos usos compatibles con estos elementos.
} 
y uso del territorio de diciembre de 1978 prioriza la política del "riuso" urbano y es también clara a la hora de relacionar la ciudad con su territorio. Así, en el artículo 35 señala que la finalidad del Plan General en este aspecto es:

La promoción, en el marco del control público, de la recuperación, valoración e integración en el contexto territorial del patrimonio edificado y del patrimonio urbanístico existente.

A las cinco categorías apuntadas en la Ley de Vivienda de 1978 esta Ley Regional añade un nuevo criterio de restauración integral (la Ley la denomina científica, pero puede confundirse con el criterio aplicado por Camilo Boito a comienzos de siglo), de enorme interés y consecuencias para futuras actuaciones en los centros históricos ${ }^{7}$. Este tipo de intervención contempla los siguientes puntos:

1. La restauración de los aspectos arquitectónicos o la restitución de las partes alteradas, comprendiendo:

1.1. Restauración o restitución de las fachadas exteriores o interiores.

1.2. Restauración o restitución de los ambientes internos.

1.3. Reconstrucción filológica de partes del edificio eventualmente hundidas o demolidas.

1.4. Conservación o restitución de la distribución y organización original de las plantas.

1.5. Conservación o restitución de los espacios libres.

2. La consolidación, con sustitución de las partes no recuperables y sin modificación de su posición o dimensiones, de los siguientes elementos:

2.1. Muros de carga, tanto interiores como exteriores.

2.2. Forjados y bóvedas, escaleras, cubiertas, etc.

3. La eliminación de las partes añadidas que se reconozcan como contradictorias respecto a la organización espacial original y sus ampliaciones orgánicas.

4. La inserción de instalaciones tecnológicas e higiénico-sanitarias esenciales, respetando las normas señaladas en los puntos precedentes.

\footnotetext{
${ }^{7}$ Un análisis completo de esta legislación regional en: "La normativa de rehabilitación y recuperación del patrimonio residencial y urbano deteriorado en la legislación urbanística regional: Emilia-Romagna". (Pol, 1980: 52 y ss).
} 
Poco antes, coincidiendo con la publicación de la Carta Europea del Patrimonio Arquitectónico (1975), se elabora para la ciudad de Ferrara la Variante del Piano Regolatore Generale con el objetivo primordial de introducir, dentro de un plan que funcionaba relativamente bien, un equilibrio en el desarrollo urbano y territorial, encaminado a combatir la diferenciación entre barrios urbanos y zonas rurales, y también el fomento de la especulación de intereses privados. Por primera vez, el desarrollo de la ciudad viene estrechamente unido al del territorio.

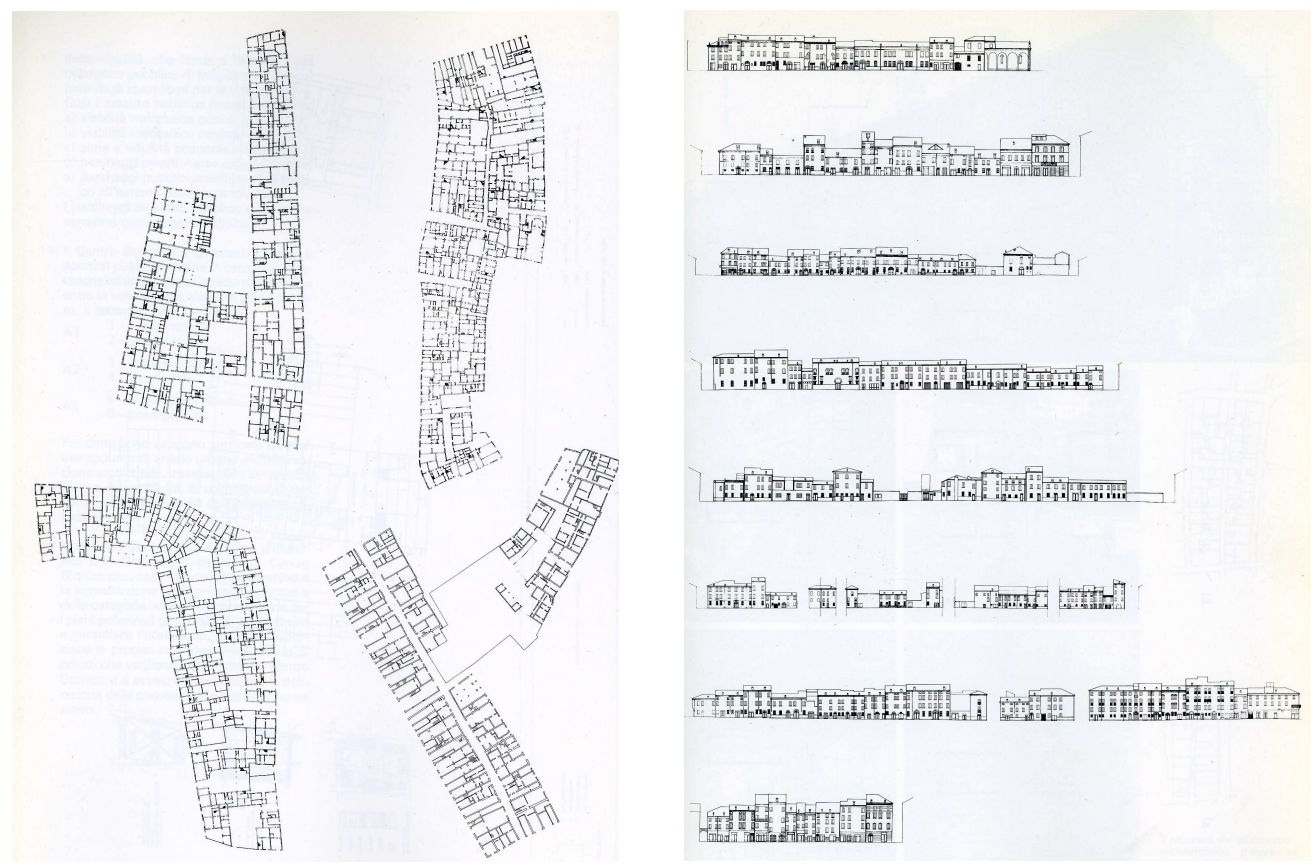

Ferrara. Piano Regolatore Generale. Análisis de la trama urbana y tipologías de la edificación medieval

La colocación de las nuevas áreas productivas, la potenciación de las redes viaria y ferroviaria, la mejora de los servicios en las zonas rurales, se insertan a su vez con coherencia en un cuadro más grande con el que la región de la Emilia-Romagna pretende combatir las actuales tendencias a la urbanización indiscriminada con el distanciamiento de los asentamientos productivos de aquellos propios de recursos locales. A la mejora en el equilibrio campociudad se unen también como elementos prioritarios del nuevo plan la recuperación y utilización óptima del patrimonio arquitectónico existente, revalo- 
rizando los viejos barrios, recuperando su trama urbana, sus volúmenes arquitectónicos, sus funciones y usos ${ }^{8}$.

Cuando se aplican los criterios de esta Variante a la conservación del Centro Histórico es cuando podemos hablar de conservación integral, recuperando y conservando todos los elementos originales (tejido edilicio menor, monumentos, murallas, jardines y huertos) sin necesidad de demoliciones ni reconstrucciones historicistas, eliminando pastiches y recuperando funciones. No solo hay que conservar el escenario (fachadismo) sino también las formas, los usos, las funciones, los volúmenes, adaptándolos a las nuevas necesidades. La Variante enmarca la conservación del Centro Histórico dentro de un proyecto de modificación del desarrollo urbano que controle y limite la expansión periférica, reestructurando y renovando el área urbanizada actual, revitalizando el Centro Histórico como núcleo de esta área al servicio de sus habitantes y de todos los ciudadanos. El Plano propone, en esencia, conservar, junto al ambiente físico, la población y las actividades económicas tradicionales del Centro Histórico (comerciantes, artesanos...), provocando con ello una inversión en la tendencia a despoblar el centro histórico para convertirlo en zona de servicios. La puesta en práctica del plan necesita la participación del Ayuntamiento para la utilización del patrimonio público con nuevos usos, las ayudas para restauración a los pequeños propietarios, etc.: el centro tiene que dar al ciudadano todos los servicios que necesita y para eso hay que readaptar los edificios y favorecer también el alojamiento de la población.
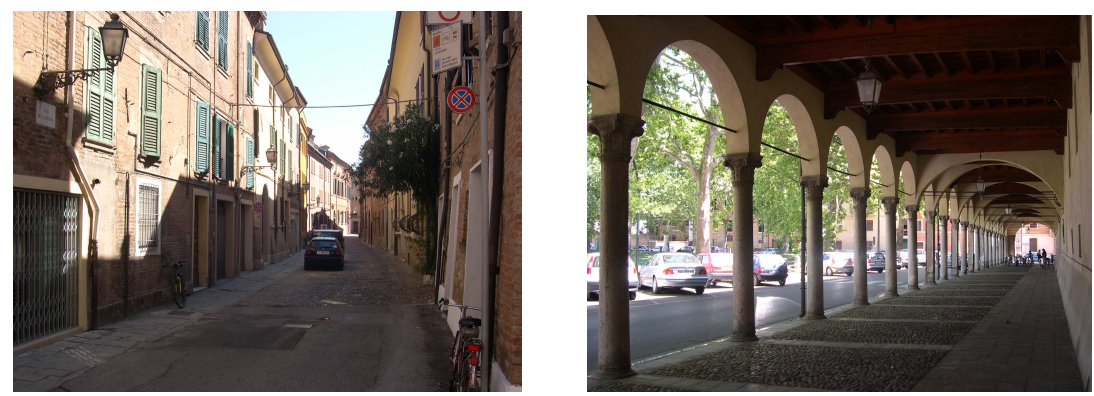

\footnotetext{
${ }^{8}$ Sobre las peculiaridades de esta Variante al Piano Regolatore Generale de 1975 y especialmente su repercusión en el Centro Histórico de Ferrara ver: Carlo Cesari. "Il Piano Regolatore ed il programma di recupero e valorizzazione del Patrimonio architettonico di Ferrara". (Cesari, 1980: 56-97).
} 


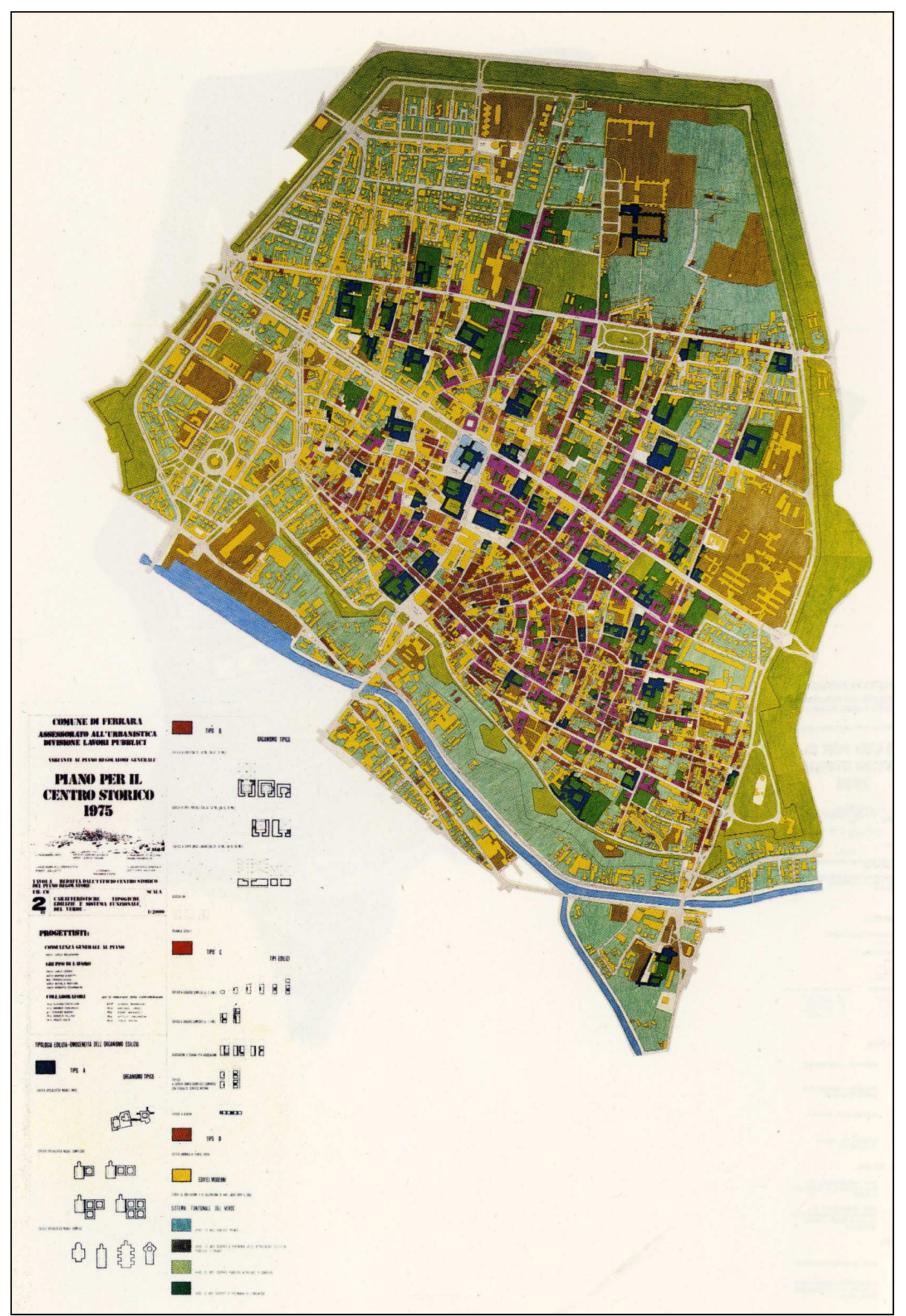

Ferrara, Centro Storico (1975). Análisis de las características tipológicas 


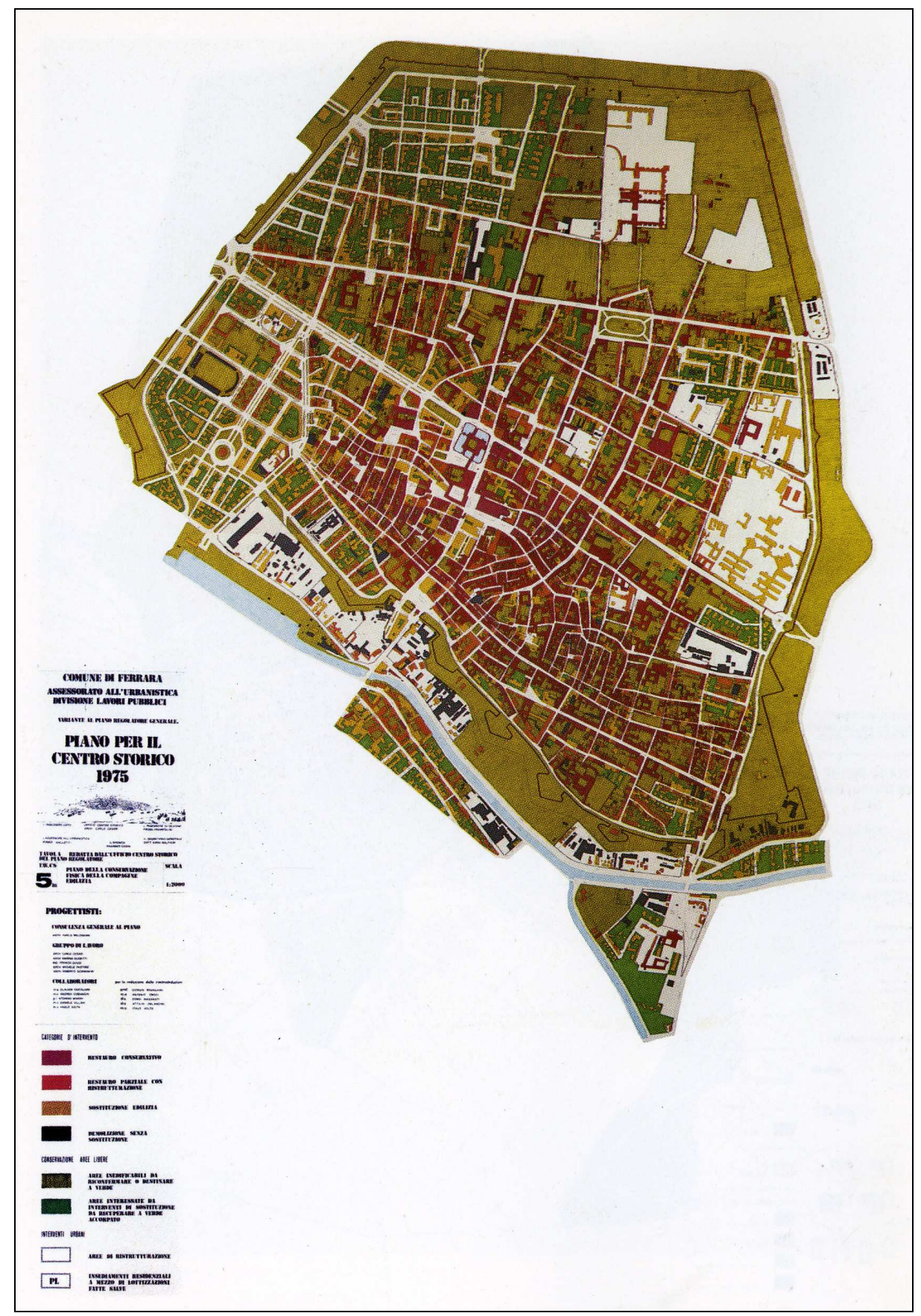

Ferrara, Centro Storico (1975). Programa de conservación del patrimonio arquitectónico

Arte y Ciudad - Revista de Investigación № 3 - Abril de 2013 
Se han señalado cinco objetivos básicos dentro de los criterios generales con los que se ha desarrollado el plan:

- Preservar de la destrucción el patrimonio preexistente.

- Integrar el patrimonio artístico, histórico y cultural en el contexto social y económico del territorio, confiándoles un papel activo y compatible.

- Descentralizar todos los generadores de direccionalidad reconocidos como incompatibles con la estructura antigua, mediante la creación de nuevas áreas de desarrollo terciario externas al núcleo antiguo, restableciendo así a la vieja ciudad su intrínseca eficacia funcional y, al mismo tiempo, otorgándole un papel más amplio de articulación en el nuevo programa territorial.

- Dotar al centro histórico de todos los estándares y servicios necesarios.

- Favorecer la peatonalización del centro, el transporte público y, en definitiva, la viabilidad urbana.

Lo que se había iniciado en 1975 como Revisión del Plan General empezará a ser una realidad a partir de 1978. En esencia, lo que se había puesto en cuestión a partir del Plan de Bolonia era la conceptualización de términos como "Monumento", "Entorno Monumental" o "Centro Histórico", a favor del concepto global de "Ciudad". Es la ciudad la que hay que conservar en su integridad, liberándola de los últimos y devastadores cambios de uso, de la terciarización de los centros urbanos, a favor de los colectivos expulsados (pobres, obreros, ancianos) que se pretende recuperen los recintos históricos como lugar de residencia y no de servicios.

En medio de esta importante renovación de criterios, en el Symposium Europeo sobre Patrimonio Arquitectónico organizado por el Consejo de Europa precisamente en Ferrara en octubre de 1978, Bruno Zevi, el gran defensor de la ciudad y de su arquitecto Biagio Rossetti, introducirá un nuevo y decisivo elemento al defender la modernidad como necesario freno a los falsos históricos que se han venido sucediendo en épocas precedentes:

La tutela y protección de los monumentos, de los ambientes, de los centros históricos, de los paisajes urbanos y de los territorios es un logro específico de la cultura moderna, no de la académica y restauradora. Ningún representante de la vanguardia, ningún arquitecto auténticamente moderno, ha desfigurado jamás un monumento, un centro histórico, un ambiente o un paisaje. Sería de todo punto impensable que un Terragni, un Persico, un Pagano o un Albini hubiesen perpetrado una 
violación de Ferrara como la que hizo Marcello Piacentini. Los "sventradores", los vándalos, los asesinos, jamás han pertenecido a la vanguardia, al contrario, la han combatido con ferocidad en nombre de las glorias romanas, medievales y renacentistas, glorias de las que no entienden ni jota y por eso ensucian con actos oprobiosos. No hablo tanto de la especulación inmobiliaria, siempre aliada con los arqueólogos del régimen y con los rectores del pasado, sino sobre todo de los estudiosos y filólogos, de los clasicistas que han dominado durante años la historiografía arquitectónica y urbanística europea. Aquí en Ferrara, junto a la gesta de Piacentini se cuenta también la de Gustavo Giovannoni, que impuso una restauración criminal, claramente anticientífica, en el patio del palacio de Ludovico el Moro, con la única finalidad de dar al palacio una fisonomía pseudobramantesca, destrozando conscientemente la originalísima y explosiva imagen del genio de Biagio Rossetti.

Después de estas nefastas pruebas, de las que tenemos ejemplos en cada ciudad italiana y europea, teorizar sobre el ostracismo de los signos de modernidad en la restauración de lo antiguo parece absurdo, pero es cuanto acontece en muchas regiones del continente, al lema de una moda restauradora a la que se han vinculado también con excesiva frecuencia apasionados administradores de izquierdas. Venciendo aquella autocensura, aquella "ley del silencio" que tanto ha dañado a la cultura de izquierdas, se confirma que la tutela de los monumentos y de los centros históricos debe ser entendida de la manera más rigurosa y, ¿por qué no?, también "global", a condición, no obstante, de excluir todos los falsos históricos, el falseamiento de balcones, de un portal, de un barrio o de un conjunto. No debería prevalecer en Emilia o en cualquier otra región la mala costumbre de desterrar la arquitectura moderna obligando a los arquitectos a mimar o reinventar arbitrariamente edificios desaparecidos hace tiempo, evocando formas sobre la base de viejas estampas, ni tampoco establecer como sistema una actitud reaccionaria encubierta de coartadas progresistas. Es nuestra obligación y deber elevar una enérgica protesta en nombre de lo antiguo y de lo moderno, del pasado por el futuro $y$, aún más, del presente por nuestro futuro. De Albini a Scarpa, de los B.B.P.R. a Piero Bottoni, al que es obligado recordar también aquí por sus obras ferraresas, Italia, no menos que otros países europeos, está llena de testimonios de artistas modernos capaces de realizar ejemplares restauraciones. No se comprende, por tanto, qué motivos nos llevan hoy a retornar al pasado y a hacer falsas restauraciones, pseudopintorescas, de escenografía provincial, que no hacen más que ofender lo antiguo y mortificar lo moderno ${ }^{9}$.

\footnotetext{
${ }^{9}$ Bruno Zevi en (Cesari, Carlo [a cura di] 1980: 124-125).
} 
Así las cosas, carece de sentido hablar ya de "Centro Histórico" como recinto acotado de especial densidad "Monumental" y cuyo valor se deriva de edificios del pasado que han permanecido al margen de cualquier desarrollo. Tiene sentido, por el contrario, hablar de Ciudad, de tejido urbano y, sobre todo, del conjunto indisoluble ciudad-ciudadano, cuyas interrelaciones son profundas y cuya trascendencia es más importante que la simple conservación de imágenes y escenarios. También tiene sentido ahora hablar de las intensas relaciones de la Ciudad con su territorio, y precisamente el Plan de Ferrara es buen ejemplo de ello. Por el contrario, pierde sentido la definición y acotación del concepto de "Monumento", así como una filosofía de su conservación que margine la consideración del devenir físico y social de la Ciudad.

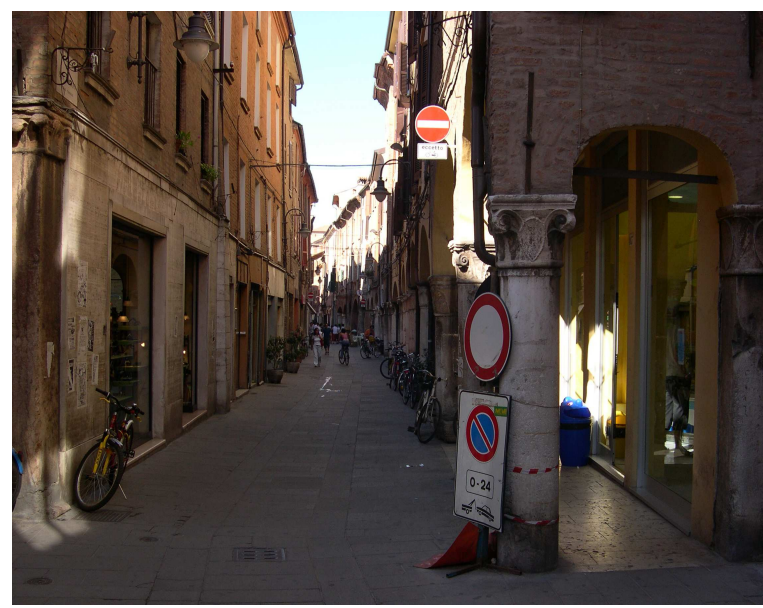

La consecuencia evidente será la formulación del principio de "conservación total" propuesto por la Declaración de Ámsterdam de 1975, sobre bases de análisis científico, poniéndose en evidencia que la conservación rigurosa del escenario físico no basta para el mantenimiento de la vitalidad del organismo urbano antiguo como corazón de la ciudad en expan-

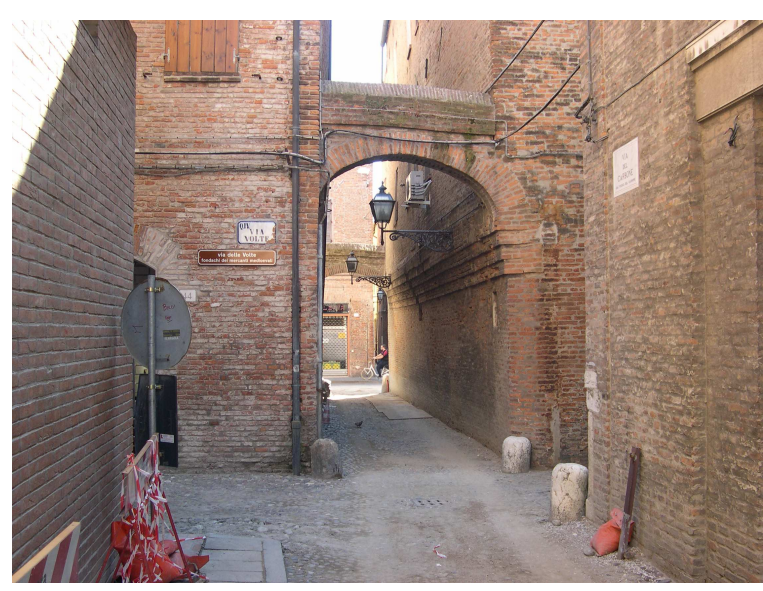

170 sión. La propuesta de Bolonia, y la consecuente Carta Europea del Patrimonio de 1975, significa un cambio profundo de actitud: de la ciudad renovada por sustitución de sus elementos, a la ciudad recuperada, restaurada y rehabilitada. No solamente en sus arquitecturas, sino también en sus estructuras sociales deterioradas por el desarrollo industrial. El cambio 
es sustancial y de enormes consecuencias. El punto final lo pondrá la Carta Europea del Patrimonio proponiendo el modelo de Conservación Integral desarrollado desde entonces, favoreciendo con ello la reutilización y, por tanto, rehabilitación de edificios, y no la nueva construcción a la que nos habían acostumbrados las políticas precedentes ${ }^{10}$.

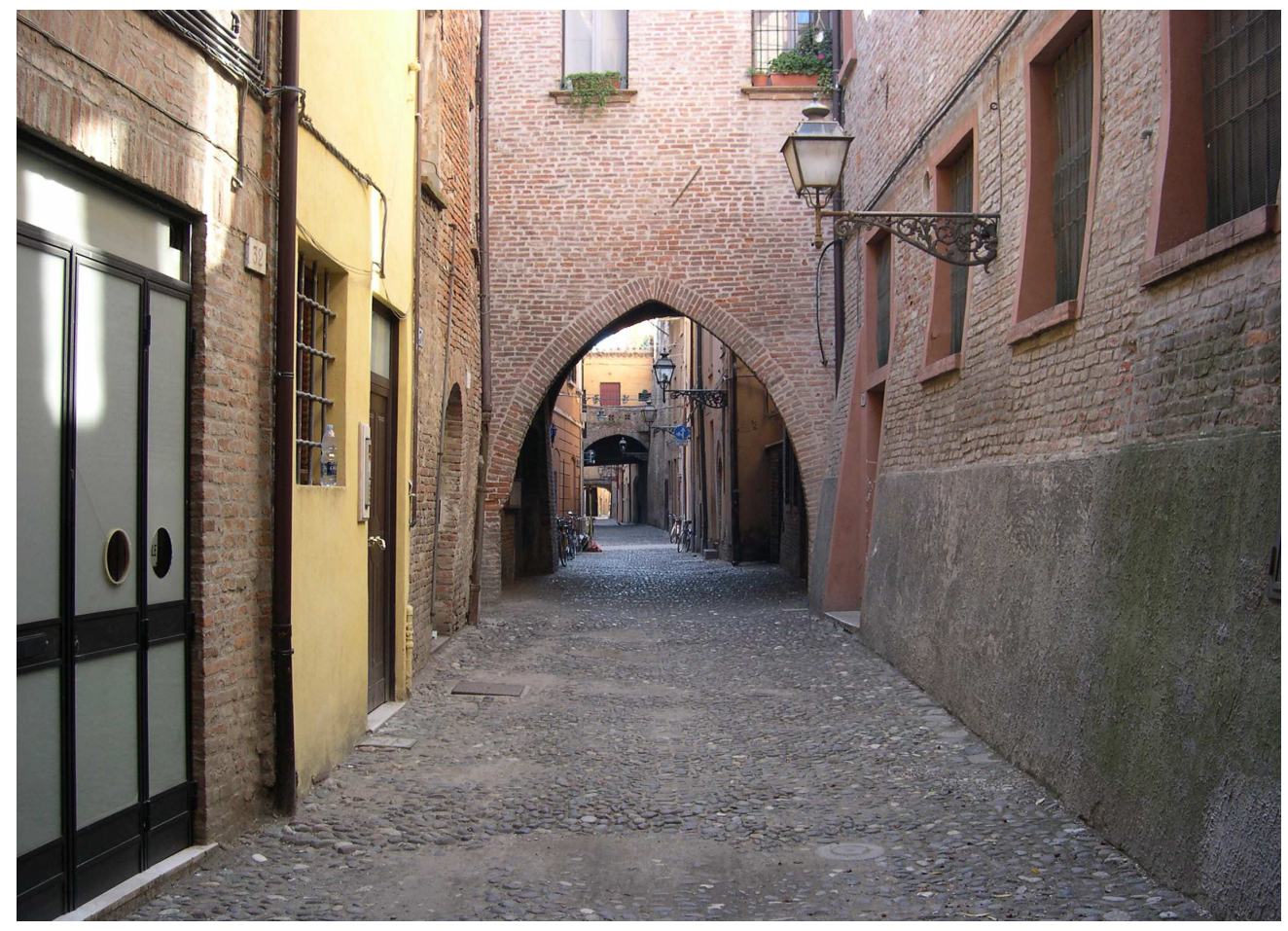

\footnotetext{
${ }^{10}$ Por conservación integral hoy se entiende, habitualmente, una intervención conexa esencialmente con la reutilización óptima del patrimonio arquitectónico existente. La solución de los problemas de recuperación desde el punto de vista de una restauración tipológica y tecnológica, por tanto, tiene que estar dirigida a alcanzar condiciones de habitabilidad de la vivienda satisfactorias y una adecuada organización de las facilidades sociales pertinentes. Es decir, la conservación es llevada a cabo y, por tanto, es considerada como "integral" a través de la restauración, dirigida principalmente a proporcionar viviendas funcionales y servicios efectivos; una restauración y una readaptación dirigidos a la optimización, de manera total y situacional, de "todas" las construcciones existentes, tanto históricas como recientes. Se trata, prácticamente, de una reutilización de lo construido, indicando con el término "reutilización" una operación de reinserción en el mercado de la vivienda de un patrimonio actualmente inutilizado o infrautilizado. El objetivo es no sólo el de impedir inútiles despilfarros, sino también de oponerse, en un régimen de tendencia a crear un contingente, como el actual, a inversiones injustificadas en nuevas construcciones. (Cesari, 1982: 1).
} 
Ferrara, en definitiva, venía a concluir el discurso de los anteriores análisis y modelos ejemplares, recapitulando y poniendo ahora el problema en las relaciones entre el patrimonio arquitectónico y el territorio circundante.

El Plan, por lo tanto, no se considera como un instrumento cerrado y bloqueado sino utilizable por parte de los instrumentos de la participación, que pueden adaptarlo a las necesidades reales a través de planes operativos sucesivos, como los planes multianuales, los planes de la "vivienda" y los planes de los "servicios". De tal manera se facilita un tipo de planificación "continua", que se adapta a las necesidades; lo cual es imposible en el ámbito de los instrumentos urbanísticos tradicionales, organizados según esquemas normativos vinculantes o preceptivos. La correspondencia con los recursos económicos y sociales disponibles o programables pasa a ser la condición de "viabilidad" del Plan; de ahí la importancia de la conexión directa entre plan, presupuestos y planes multianuales de inversión pública, atribuyendo al primero las elecciones prioritarias para la formación y a los otros los medios de realización ${ }^{11}$.

En líneas generales el Plan se dirigió fundamentalmente a la conservación del patrimonio arquitectónico, planteando además el principio de la conservación ampliada desde el Centro Histórico (capital de provincia) a todas las obras arquitectónicas de su territorio, en una relación de equilibrio entre ciudad y campo.

La novedad del Plan de Ferrara, por tanto, no es la manera en que ha sido preparado o planteado, sino el haber instaurado una relación estricta entre la política de intervención en el Centro Histórico y las políticas de los espacios periféricos y el territorio. Esto supone la introducción de una clara voluntad de limitar la expansión urbana, tomando como nuevo tema orientativo, más que la construcción de un nuevo ensanche, el tratamiento de todo lo existente, formado sobre todo por el Centro Histórico pero no exclusivamente por éste. El entendimiento del verdadero carácter del centro histórico y de su organicidad con respecto al territorio, conlleva como consecuencia el entendimiento de la periferia como una parte de la ciudad de la que el centro histórico vuelve a ser el punto de partida. La entidad-periferia que está creciendo alrededor y que por su misma naturaleza no encontraría nunca un momento de equilibrio estable, se pone en una situación de equilibrio a través de una aclaración de la relación que debe

\footnotetext{
${ }^{11}$ Cesari, Carlo, (1982) op. cit.
} 
existir entre la ciudad edificada y el territorio que la rodea. Por tanto, el término de Centro Histórico evoluciona de un concepto de identificación física perimetrada a uno de relación vital entre población y medio ambiente, y se amplía el campo de aplicación de la salvaguardia a todo lo que es testimonio cultural. Ya no existen juicios de valor, como "monumental", "pobre", "turístico", etc., ni de dimensión, como "grande", "pequeño" o "mediano", para el centro histórico. La referencia es la de un sistema de vida, de valores culturales y civiles.

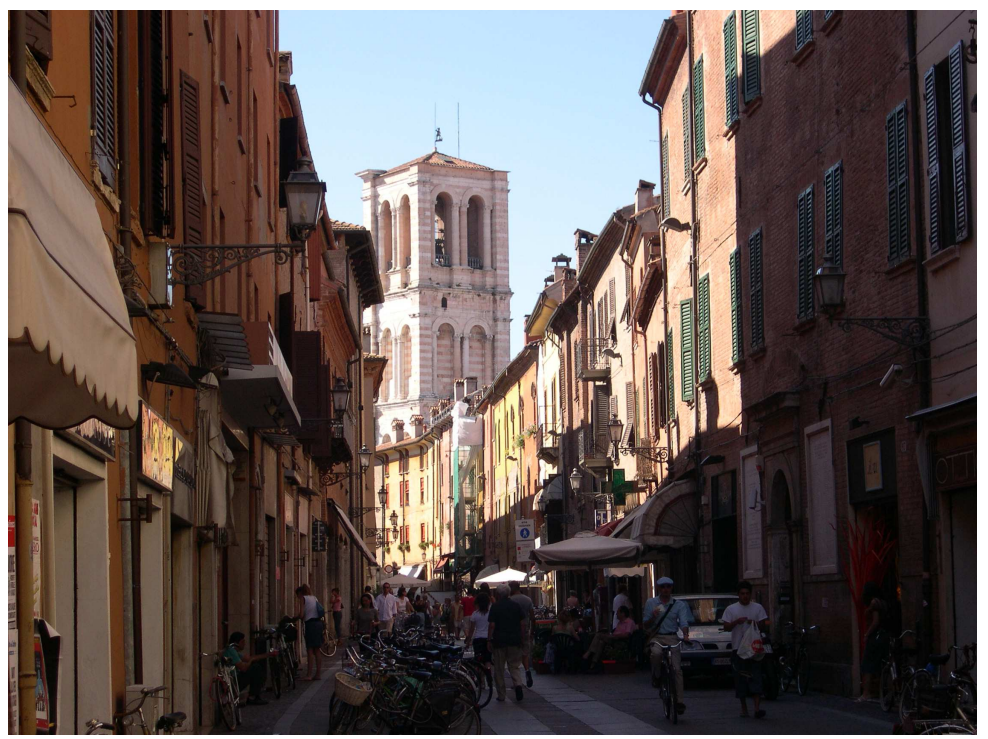

Quinientos años después, los valores más significativos de la ampliación de Rossetti se encuentran de nuevo en la ciudad. La planificación general, el control de todos los elementos, la conexión arquitectura-urbanismo, todo, en definitiva, planteaba un criterio "integral" de tratamiento de la ciudad que, trasladado a nuestro tiempo ha devenido en "conservación" o "rehabilitación integral del centro histórico".

El Centro Histórico, o mejor, el conjunto histórico, en la perspectiva de su desarrollo, permite perpetuar, como en el pasado, la continuidad de la civilización sin destrucciones o adaptaciones, en una óptica progresista y no estática, con la conciencia por nuestra parte de que proteger el pasado no significa cristalizar o museificar, sino garantizar el crecimiento progresivo de la cultura actual, a través del conocimiento perfecto y el disfrute de los testimonios que produjeron esta misma civilización (Cesari, 1982: 3). 


\section{Bibliografía}

BASSI, Carlo (1980): Nuova guida di Ferrara. Vita e spazio nell'architettura di una città emblematica. Boloventa Editore, Milano/Ferrara.

BASSI, Carlo (2003): Perché Ferrara è bella. Guida alla comprensione della città. Grabriele Corbo Editore, Ferrara/Roma (terza edizione).

BocCHI, Francesca (1974): “Note di storia urbanistica ferrarese nell'alto medioevo". Atti e Memorie Dep. Ferrarese di Storia Patria. Vol. XVIII.

BURCKHARDT, Jacob (1983): La cultura del Renacimiento en Italia. Basilea, 1860. Reedición Iberia, Barcelona.

CAMPOS VenUtI, Giuseppe (1994): "Cincuenta años: tres generaciones urbanísticas". Cincuenta años de urbanismo en Italia, 1942-1992. BOE y Universidad Carlos III, Madrid.

CESARI, Carlo (a cura di) (1980): Il passato per un nostro avvenire. Atti del $6^{\circ}$ symposium europeo sul patrimonio architettonico promosso dal consiglio d'Europa nell'ottobre del 1978 a Ferrara sul tema "Vitalità delle compagini storiche, fattore e prodotto di riequilibrio tra città e campagna". Comune di Ferrara, Ferrara.

CESARI, Carlo (1982): "Criterios de intervención en el Centro Histórico". Actas de las I Jornadas de Patrimonio Histórico-Artístico. Junta de Castilla y León, Burgos.

CESARI, Carlo (1989): "El proceso de conservación y rehabilitación en Italia". Actas I Congreso Ciudades Patrimonio de la Humanidad. Cámara de la Propiedad Urbana, Segovia.

CHAVES MARTín, Miguel-Angel (2001): Ferrara (1492-1992). Arquitectura y Ciudad. Editorial Complutense, Madrid.

CHAVES MARTíN, Miguel-Angel (2012): “La ciudad como obra de arte. Un nuevo modelo de ciudad en la Italia del Renacimiento: Ferrara (14921505)". Arte y Ciudad. Revista de Investigación. № 2, octubre de 2012, pp. 155-178. Universidad Complutense, Madrid.

FRANCESCHINI, Adriano (1969): I frammenti epigrafici degli Statuti di Ferrara del 1173 venuti alla luce nella Cattedrale. Ferrariae Decus e Deputazione Storia Patria, Ferrara.

GARCíA GIL, Alberto (1989): “El Patrimonio Arquitectónico en el final del siglo". Actas I Congreso Ciudades Patrimonio de la Humanidad. Cámara de la Propiedad Urbana, Segovia.

GUNDERSHEIMER, Werner L. (1988): Ferrara Estense. Lo stile del potere. Panini Edizioni, Modena/Ferrara. 
MARCiAnÒ, Ada Francesca (1992): L'età di Biagio Rossetti. Rinascimenti di casa d'Este. Gabriele Corbo Editore, Roma/Ferrara.

PAPAGNO, Giuseppe - QUONDAM, Amedeo (a cura di) (1982): La corte e lo spazio: Ferrara estense. Bulzoni, Roma.

POL, Francisco (1980): La política de rehabilitación urbana en Italia. MOPU, Madrid.

TUOHY, Thomas (1996): Herculean Ferrara. Ercole d'Este (1471-1505) and the invention of a ducal capital. Cambridge University Press.

ZEVI, Bruno (1960): Biagio Rosseti architetto ferrarese, il primo urbanista moderno europeo. Einaudi, Torino.

ZEVI, Bruno (1971): Saper vedere l'urbanistica. Ferrara di Biagio Rossetti, la prima città moderna europea. Einaudi, Torino. 